\title{
Phenolic compounds in juice of "Isabel" grape treated with abscisic acid for color improvement
}

\author{
Lilian Yukari Yamamoto ${ }^{1}$, Renata Koyama ${ }^{1}$, Adriane Marinho de Assis ${ }^{2}$, Sergio Ruffo Roberto ${ }^{1}$, Yuri Renan Bovolenta ${ }^{3}$, \\ Suzana Lucy Nixdorf ${ }^{3}$, Esteban García-Romero ${ }^{4}$, Sergio Gómez-Alonso ${ }^{5}$, and Isidro Hermosín-Gutiérrez ${ }^{5, a}$

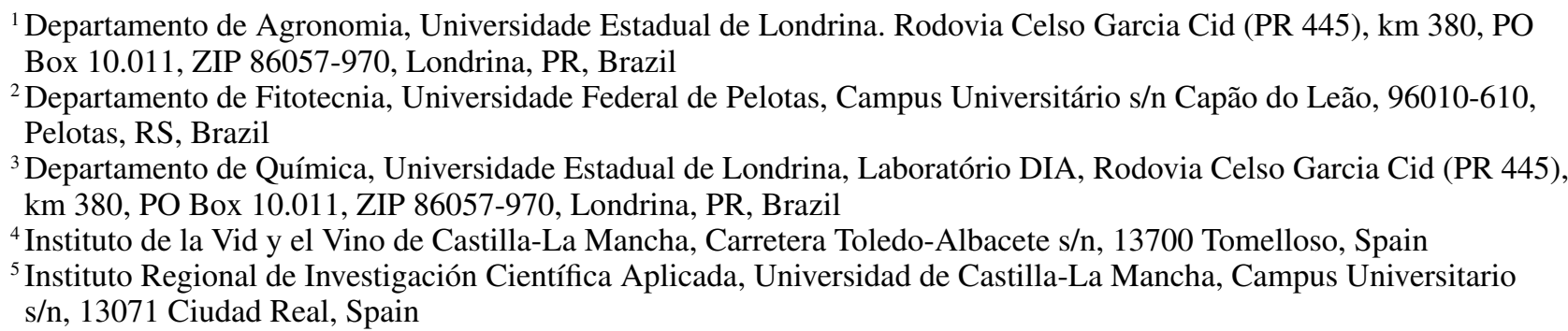

\begin{abstract}
Isabel grape is the main cultivar used to produce juice in Brazil, which has rusticity and high productivity, but it is deficient in anthocyanins, a pigment responsible for the color. Thus, an alternative is the application of abscisic acid ( $S$-ABA), which is responsible to promote the synthesis of anthocyanins. The aim of this work was to evaluate the phenolic compounds composition in "Isabel" grape juice treated with $S$-ABA, by HPLC-DAD-ESI-MS/MS technique. The results showed the increasing in total anthocyanin concentration in juices, with $S$-ABA treatments, as well as the proportion of B-ring tri-substituted anthocyanidins. Regarding total flavonols, differences were only significant in juices obtained in 2012 season. $S$-ABA treatments did not significantly affect the hydroxycinnamic acid derivatives, flavan-3-ols, resveratrol and antioxidant capacity of juices. Juice from "Isabel" grapes treated with $S$-ABA provides an enhancement of total anthocyanin concentration, mainly when grapes are treated before or at the onset of véraison.
\end{abstract}

\section{Introduction}

In some countries such as United States and Brazil, american grapes (Vitis labrusca) are the main cultivars for grape juice processing, and in Brazil cv. Isabel is the most important by presenting tolerance to the main fungal diseases and high yield. However, due to lack of color, it becomes necessary to make a blend with other colored cultivars in order to increase it in juices [1].

Grape skin color development is an important event, biologically and economically, and it is determined by anthocyanins content and composition, which are flavonoids widely distributed in nature, responsible for most of the colors in flowers and fruits [2].

Various agronomic strategies have been employed to enhance the biosynthesis of phenolic compounds in fruits and vegetables, and one strategy is abscisic acid (ABA) application, a plant growth regulator involved in different physiological processes, including color development.

On grapes, the accumulation of anthocyanins begins at véraison, the onset of ripening, and seems to be regulated, at least partially, by ABA [3-5]. Many studies have demonstrated that exogenous application of an isomer of this plant growth regulator, $(S)$-cis-abscisic acid ( $S$-ABA), increases anthocyanin concentration in grape skin [6-9]. However,

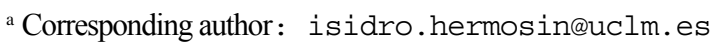

the grape cultivar, as well as the application timing, can modify the effect of this growth regulator in grapes $[7,8,10]$.

The aim of this study was to identify and quantify the phenolic compounds present in grape juice of "Isabel" grapes treated with $S$-ABA, in order to increase pigments concentration by HPLC-DAD-ESI-MS/MS technique. Phenolic compounds studies comprise anthocyanins, flavonols and hydroxycinnamic acid derivatives.

\section{Material and methods}

\subsection{Grape treatments and preparation of juices}

The field trial was conducted in a 11-year-old commercial vineyard of own-rooted "Isabel" grapes (Vitis labrusca L.) belonging to Intervin ${ }^{\circledR}$ Winery, located in Maringá, state of Paraná, Brazil $\left(23^{\circ} 25^{\prime} \mathrm{S}, 51^{\circ} 57^{\prime} \mathrm{W}\right.$, altitude $\left.542 \mathrm{~m}\right)$.

The vines were trained on overhead trellises and spaced $4.0 \mathrm{~m} \times 1.0 \mathrm{~m}$ apart. Fruit pruning was performed to leave 2-3 buds per spur. Subsequently, 5\% hydrogen cyanamide was applied to the buds to induce and standardize sprouting.

It was evaluated the effect of $S$-ABA applied to grapes at different stages of ripening, was evaluated during two consecutive crop years (regular season in December 2011, D11; and out of season in May 2012, M12). S-ABA, at an active concentration of $100 \mathrm{~g} \mathrm{~L}^{-1}$, was supplied by Valent BioSciences Corporation ${ }^{\circledR}$ (Libertyville, IL). 
The following treatments were tested: (1) Control (C), in which no $S$-ABA was applied; (2) $S$-ABA $400 \mathrm{mg} \mathrm{L}^{-1}$ applied 7 days before véraison $(\mathrm{DBV})+S$-ABA $400 \mathrm{mg} \mathrm{L}^{-1}$ at 35 days after first application (DAFA); (3) $S$-ABA $400 \mathrm{mg} \mathrm{L}^{-1}$ applied at véraison $(\mathrm{V})+S$-ABA $400 \mathrm{mg} \mathrm{L}^{-1}$ at 35DAFA; (4) $S$-ABA $400 \mathrm{mg} \mathrm{L}^{-1}$ applied 7 days after véraison $(\mathrm{DAV})+S$-ABA $400 \mathrm{mg} \mathrm{L}^{-1}$ at $35 \mathrm{DAFA}$.

Experimental design applied was randomized blocks with four treatments and five replicates, with five vines per plot.

For treatment applications, clusters were sprayed using a knapsack sprayer at a pressure of 568.93 psi (39.22 bar) with JA1 hollow cone nozzle tips at a volume of $800 \mathrm{~L} \mathrm{ha}^{-1}$ to provide complete and uniform coverage. In addition, $0.3 \mathrm{~mL} \mathrm{~L}^{-1}$ of Break Thru ${ }^{\circledR}$ (Evonik Industries, Germany) non-ionic surfactant was added to all treatments.

For each season, the harvest was determined when total soluble solids (TSS) content reached around $16^{\circ}$ Brix and whole grape juices from treatment plots were produced by the Welch process [11]. Juices were bottled at warm temperature $\left(75^{\circ} \mathrm{C}\right)$ into $1 \mathrm{~L}$ capacity sterilized polyethylene containers with lids and stored in the refrigerator at $4^{\circ} \mathrm{C}$.

\subsection{Spectrophotometric measurements}

Spectrophotometric measurements were performed in the Laboratory of Analytical Chemistry and Food Technology, Castilla-La Mancha University, Ciudad Real, Spain.

All solvents were of HPLC quality, all chemicals were of analytical grade ( $>99 \%)$, using ultrapure water. Commercial standards were used for identification. Quantitation ( $\mathrm{mg} \mathrm{kg}^{-1}$ of grape) was done as equivalents of the most representative compounds for each family of phenolic compounds.

Sugars and other polar substances of the juice samples were eliminated performing an extraction in solid phase (SPE) with Bond Elut C18 cartridges (500 mg, $3 \mathrm{ml}$; Agilient Technologies, Santa Clara, USA).

Bond Elute Plexa PCX cartridges $(200 \mathrm{mg}, 6 \mathrm{~mL}$; Agilient Technologies, Santa Clara, USA) allowed the isolation of non-anthocyanin phenolic compounds from juices extracts, and these anthocyanin-free fractions were used to analyze flavonols and hydroxycinnamic acid derivatives.

Finally, the flavan-3-ols (monomers, B-type dimers, and polymeric proanthocyanidins) and stilbenes were isolated from juices extracts using SPE on C18 cartridges (Sep-pak Plus C18, Waters Corp., Milford, MA; cartridges filled with $820 \mathrm{mg}$ of adsorbent).

\subsection{HPLC-DAD-ESI-MSn identification and quantitation of anthocyanins, flavonols and hydroxycinnamic acid derivatives in "Isabel" grape juice}

Anthocyanins and non-anthocyanin phenolic compounds from juices, namely flavonols and hydroxycinnamic acid derivatives (HCAD), were separately analyzed after adaptation of previously described methods to the use of narrow bore, smaller particle size, chromatography columns [12].

For identification, Ion Trap ESI-MS/MS detector was used in both positive (anthocyanins) and negative (flavonols and HCAD) ion modes. Identification was mainly based on spectroscopic data (UV-Vis and MS/MS) obtained from authentic standards or previously reported [13-17]. For quantitation, DAD-chromatograms were extracted at 520 (anthocyanins),
360 (flavonols) and $320 \mathrm{~nm}$ (hydroxycinnamic acid derivatives). In the case of overlapping DAD peaks, quantitation was made with the help of extracted ion chromatograms at the $\mathrm{m} / \mathrm{z}$ values of each overlapping compound: the EIC integral value was used for an estimation of contribution of each overlapping compound to the joint DAD peak.

\subsection{Identification and quantitation of flavan-3- ols and stilbenes in "Isabel" grape juice using multiple reaction monitoring HPLC-ESI-MS/MS}

For flavan-3-ol monomers and B-type dimer procyanidins and stilbenes analysis from juice, $0.30 \mathrm{~mL}$ of the SPEC18 extract was diluted with $1.5 \mathrm{~mL}$ of water: formic acid (98.5:1.5) in a chromatographic vial that was sealed, and injected into HPLC system.

The structural information of proanthocyanidins was obtained following the acid-catalyzed depolymerization induced by pyrogallol method [12].

The analysis was performed using an Agilent 1200 series system equipped with DAD (Agilent, Germany), and coupled to an AB Sciex 3200 Q TRAP (Applied Biosystems) electrospray ionization mass spectrometry system (ESI-MS/MS). The chromatographic system was managed by the Agilent Chem Station (version B.01.03) data-processing station. The mass spectra data was processed with the Analyst MSD software (Applied Biosystems, version 1.5). Two MS scan types were used: enhanced MS (EMS) for compound identification; and multiple reaction monitoring (MRM) for quantification.

\subsection{Determination of anthocyanins in "Isabel" grape juice by sodium bisulphite discoloration method and antioxidant capacity by DPPH}

Anthocyanins were also measured by sodium bisulphite discoloration method [18] and antioxidant capacity by radical DPPH [19].

\subsection{Statistical analysis}

Means results for phenolic composition were subjected to analysis of variance and compared using the StudentNewman-Keuls test at 5\% probability. Control means were compared between seasons D11 and M12, using Student's " $t$ " test at $5 \%$.

\section{Results and discussion}

\subsection{Anthocyanins in juices of "Isabel" grapes treated with S-ABA}

Treatments in which $S$-ABA was applied before and at the beginning of véraison (BV and $\mathrm{V}$, respectively) gave rise to grape juices containing significantly higher total contents of anthocyanins than the control juices in the two studied seasons (regular season of December 2011, D11; and out of season of May 2012, M12) (Table 1). However, the effect of $S$-ABA on total anthocyanins increase in grape juices showed differences according to treatment timing application on grapes: $\mathrm{V}$ treatment led to significant increases of around $73 \%$ in both harvests (D11 and M12); BV treatment significantly increased by $42 \%$ in D11 and $74 \%$ in M12; and AV treatment did not significantly increase in D11, but significantly increased by $53 \%$ in M12. 


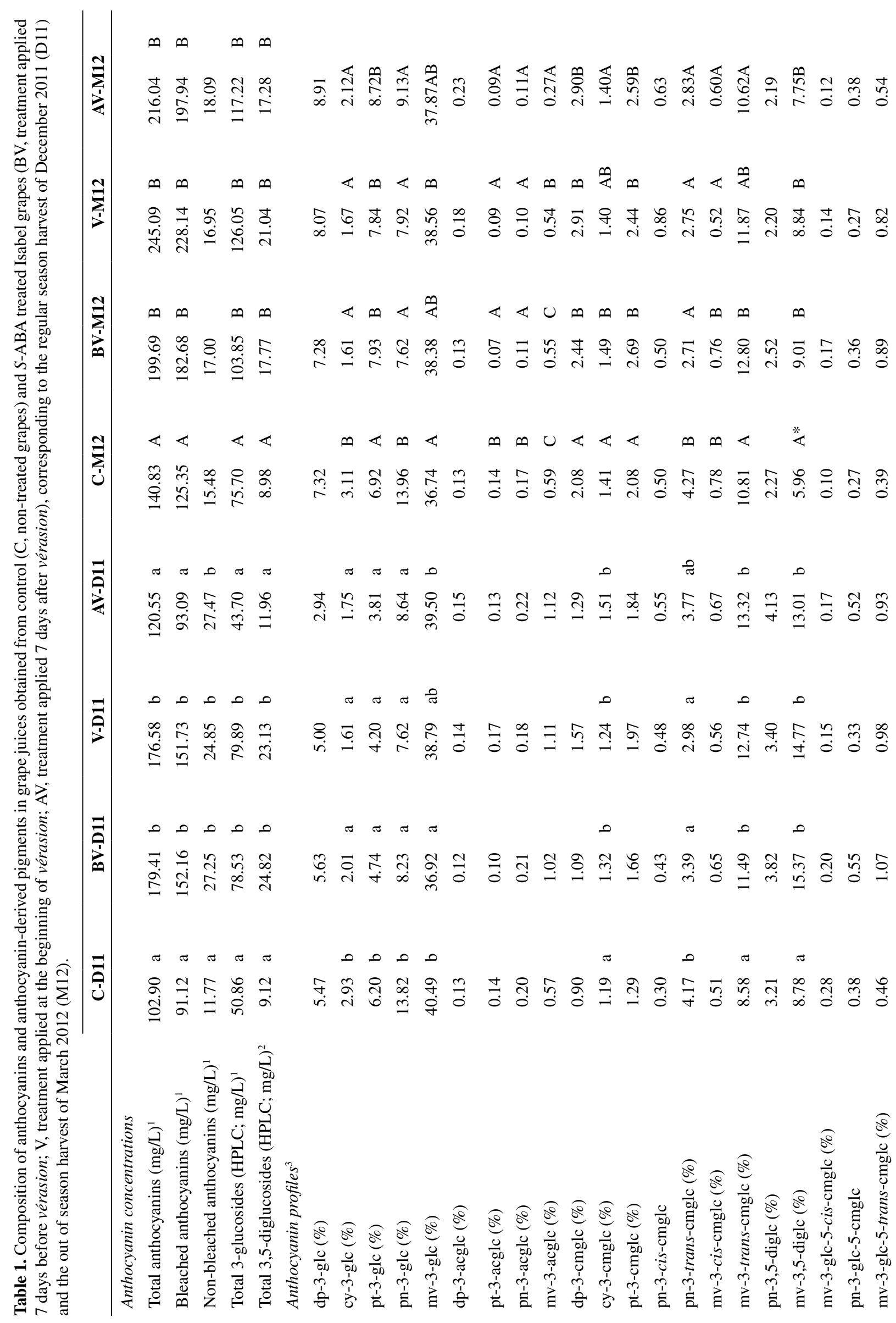




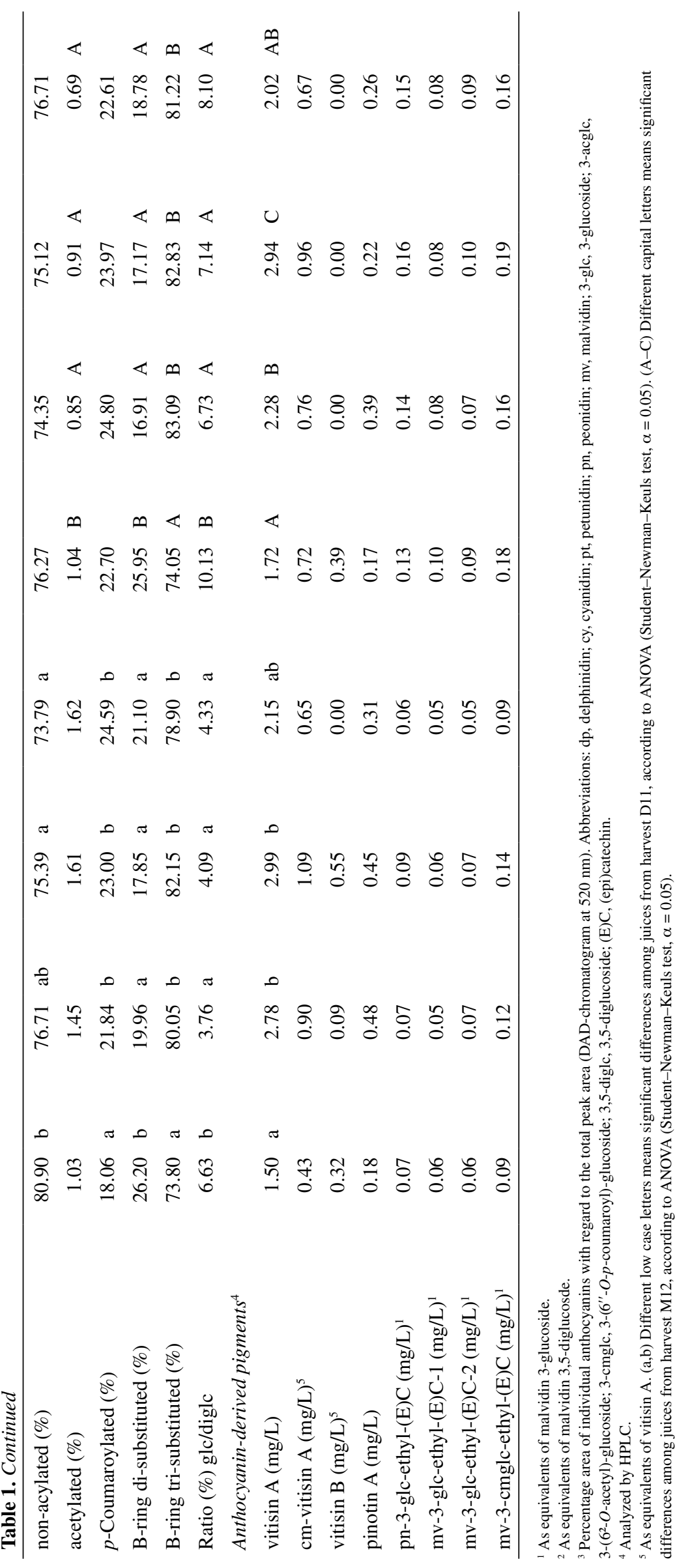


Whole grape juices obtained by steam extraction in stainless steel pot may have the initial disadvantage of promoting some thermal degradation of anthocyanins [20], but it can also promote the formation of anthocyanin-derived pigments with higher stability, like pyranoanthocyanins and polymeric tannin-anthocyanin adducts, formed by direct reaction or mediated by acetaldehyde [21-23]. Total anthocyanin-derived pigments concentration and formation of vitisin-like pyranoanthocyanins, mainly vitisin A were parallel to concentration of total anthocyanins. In contrast, the formation of hydroxyphenyl-pyranoanthocyanins like pinotin A, requires the previous release of caffeic acid by chemical hydrolysis of caftaric acid, and was observed in lesser extent that was not significantly different among treated and control grape juices in both harvests.

The anthocyanins identified in grape juices elaborated from "Isabel" grapes were in agreement with previous findings [14] and resembled those of other hybrid grape cultivars [24,12]. The main type of anthocyanins found was anthocyanidin 3-glucosides (Table 1), the most important being derived from malvidin followed by other common grape anthocyanidins (delphinidin, cyanidin, petunidin and peonidin). The 6"-O-acetyl and 6"- $O$ - $p$-coumaroyl derivatives of anthocyanidin 3-glucosides were also identified. As "Isabel" is an hybrid grape cultivar ( $V$. vinifera $\times V$. labrusca), the occurrence of anthocyanidin 3,5-diglucosides is expected, and the 3,5-diglucosides of peonidin and malvidin were identified, together with their respective 3-(6"-O-p-coumaroyl) derivatives.

The aforementioned effects can be considered as contributing to color quality of "Isabel" grape juices, not only for an enhancement of color intensity but also for the higher stability of $p$-coumaroylated anthocyanins compared to the non-acylated ones, because they can be involved in both intra- and intermolecular copigmentation complexes [25].

\subsection{Non-anthocyanin phenolic compounds in juices of "Isabel" grapes treated with S-ABA}

Flavonols are the best copigments found in grapes and derived products, contributing to color enhancement and stability, and also show great antioxidant capacity. The flavonols identified in "Isabel" grape juices were in agreement with previous results reported for "Isabel" wines [14] and many other grape cultivars and their wines [13,26,27], and comprised both 3 -glycosides and their corresponding free aglycones (Table 2).

Grape juices obtained from grapes treated with $S$-ABA showed higher content in total flavonols, although these differences were only significant in the case of juices from harvest M12 (Table 2). As also observed for anthocyanins, the treatment induced a significant increase of the proportions of B-ring tri-substituted flavonols (those based on myricetin, laricitrin and syringetin) and the subsequent lower proportions of the di-substituted structures, especially those based on quercetin.

Hydroxycinnamic acid derivatives (HCAD) are also involved in copigmentation complexes, the formation of hydroxyphenyl-pyranoanthocyanins and also oxidation reactions (browning reactions). The expected hydroxycinnamoyl-tartaric acids derived from caffeic and $p$-coumaric acids were identified in "Isabel" grape juices (Table 2). Treatments with $S$-ABA did not significantly affect the qualitative and quantitative composition of the HCAD of the control grape juices.

Regarding flavan-3-ols, low amounts of monomers and dimers could be detected in the "Isabel" grape juices, being catechin the main compound (Table 3). The treatment with $S$-ABA had little effect on the total content of flavan-3-ols and only a significant decrease was observed in the harvest of D11 that mainly affected to minor components. The total content of proanthocyanidins was also low and their structural characteristic showed they were mainly composed by dimers with low contributions of galloylated and prodelphinidin units, being catechin the main terminal unit and epicatechin the most important extension unit (Table 4). It is well known that grape skin proanthocyanidins are characterized by high degree of polymerization and important contribution of prodelphinidin units [35], in contrast to our findings. The latter results seems to reinforce the suggestion that the little expected amounts of extracted proanthocyanidins from the grape skins mainly reacted during the grape juice obtaining thermal process. The juices obtained from $S$-ABA treated grapes showed a significant lower content of proanthocyanidins which could be correlated with their also higher content of anthocyanins.

In "Isabel" grape juices, the trans and cis isomers of the 3-glucoside of resveratrol, together with trans-resveratrol were found (Table 3). Trans-resveratrol amounts and its 3-glucoside found in "Isabel" grape juices can be described as low (less than $1 \mathrm{mg} \mathrm{L}^{-1}$ of total resveratrol equivalent). The $S$-ABA treatment did not exert any significant effect on these compounds.

Finally, the presence of phenolic compounds in "Isabel" grape juice confers antioxidant capacity to this beverage, which did not significantly differ among grape treatment with $S$-ABA (Table 3 ).

The use of $S$-ABA demonstrated to act in increasing anthocyanins content in grape skins. Our results have confirmed that grape juices obtained from $S$-ABA treated grapes really contain more anthocyanins and the timing of application seems led to better results when applied before or at the onset of véraison of grapes. In addition, the anthocyanin profile suffered some change, mainly the increase of anthocyanin 3,5-diglucosides and $p$-coumaroylated anthocyanidin 3 -glucosides proportions. The $S$-ABA treatment also had effect on the content of other non-anthocyanin phenolic compounds content, like flavonols, which share some of the biosynthesis pathway with anthocyanins. Flavonols also increased their total content in the grapes juices obtained with treated grapes, although this increase was only significant in the case of samples with the initial lowest content, those of harvest M12. In spite of the improvement concerning to the phenolic composition directly (anthocyanins) or indirectly (flavonols) related to the red color of "Isabel" grape juices, the treatment with $S$-ABA had no significant influence on antioxidant capacity of these beverages.

The authors are grateful for the scholarship provided by CAPES (PDSE) and CNPq, as well as Valent BioSciences Corporation ${ }^{\circledR}$ for providing $S$-ABA. 


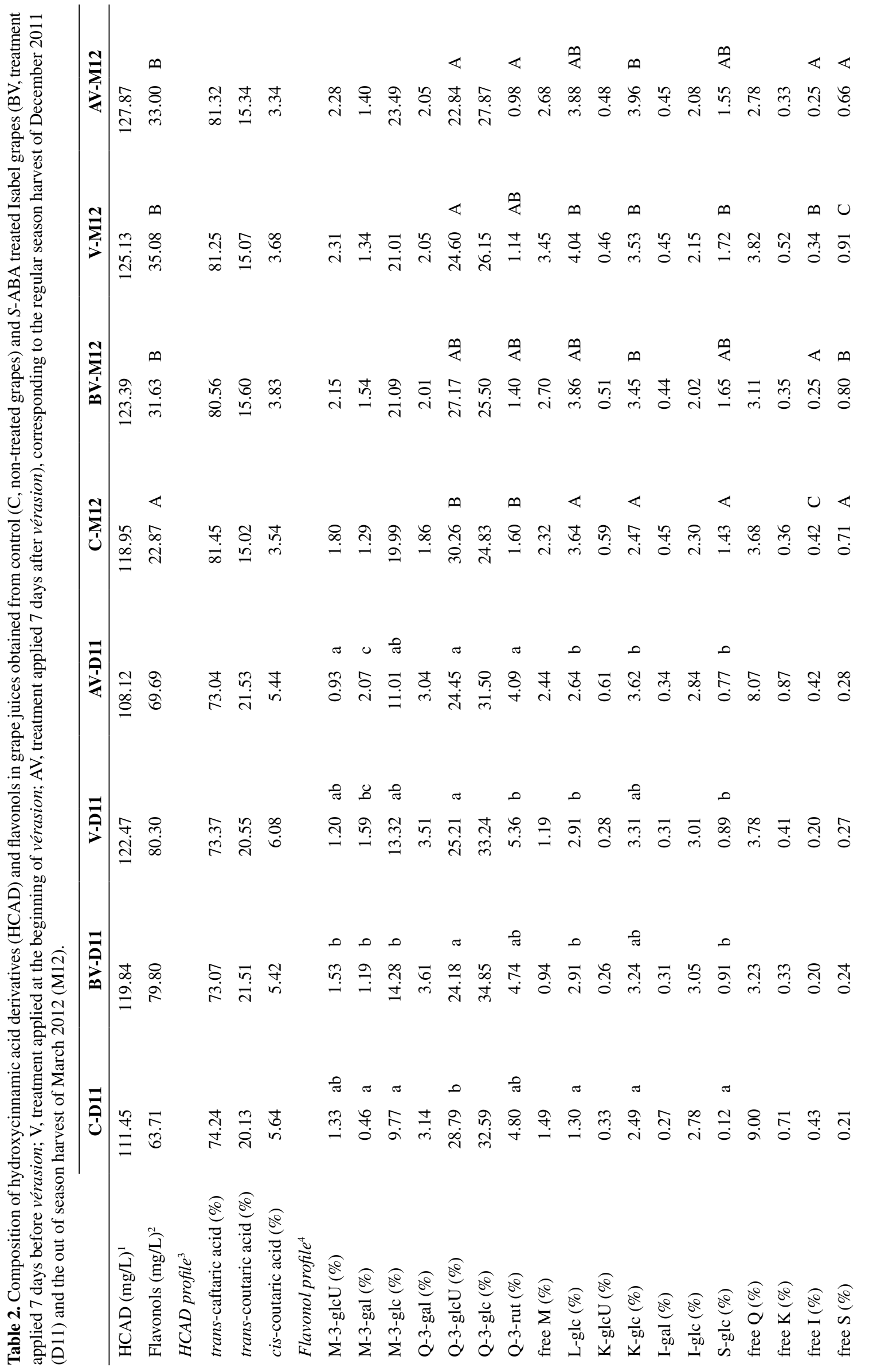




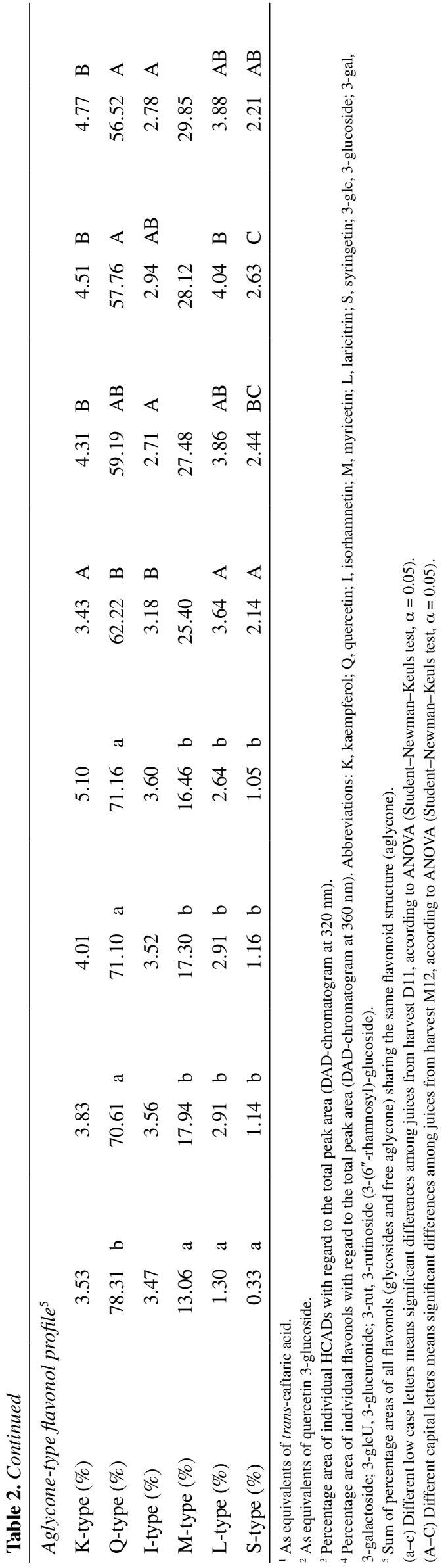


BIO Web of Conferences

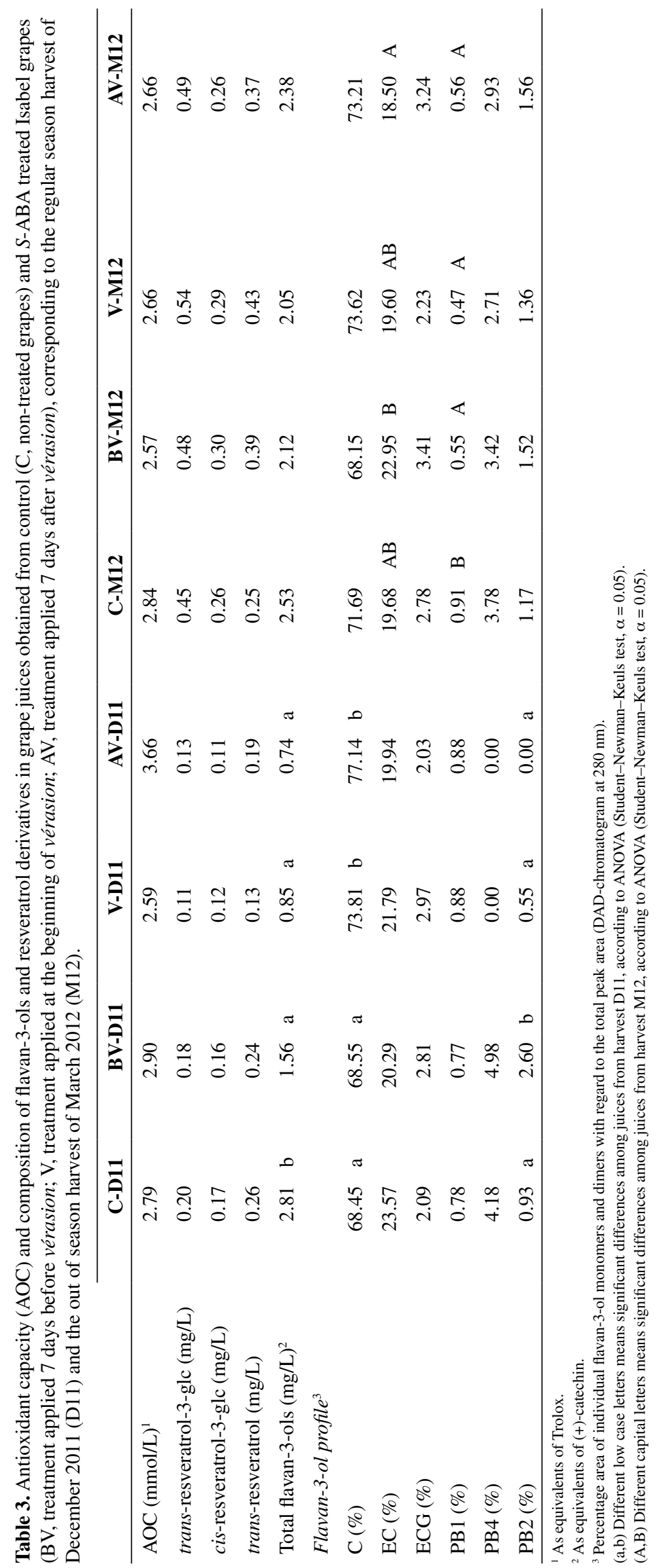


$38^{\text {th }}$ World Congress of Vine and Wine

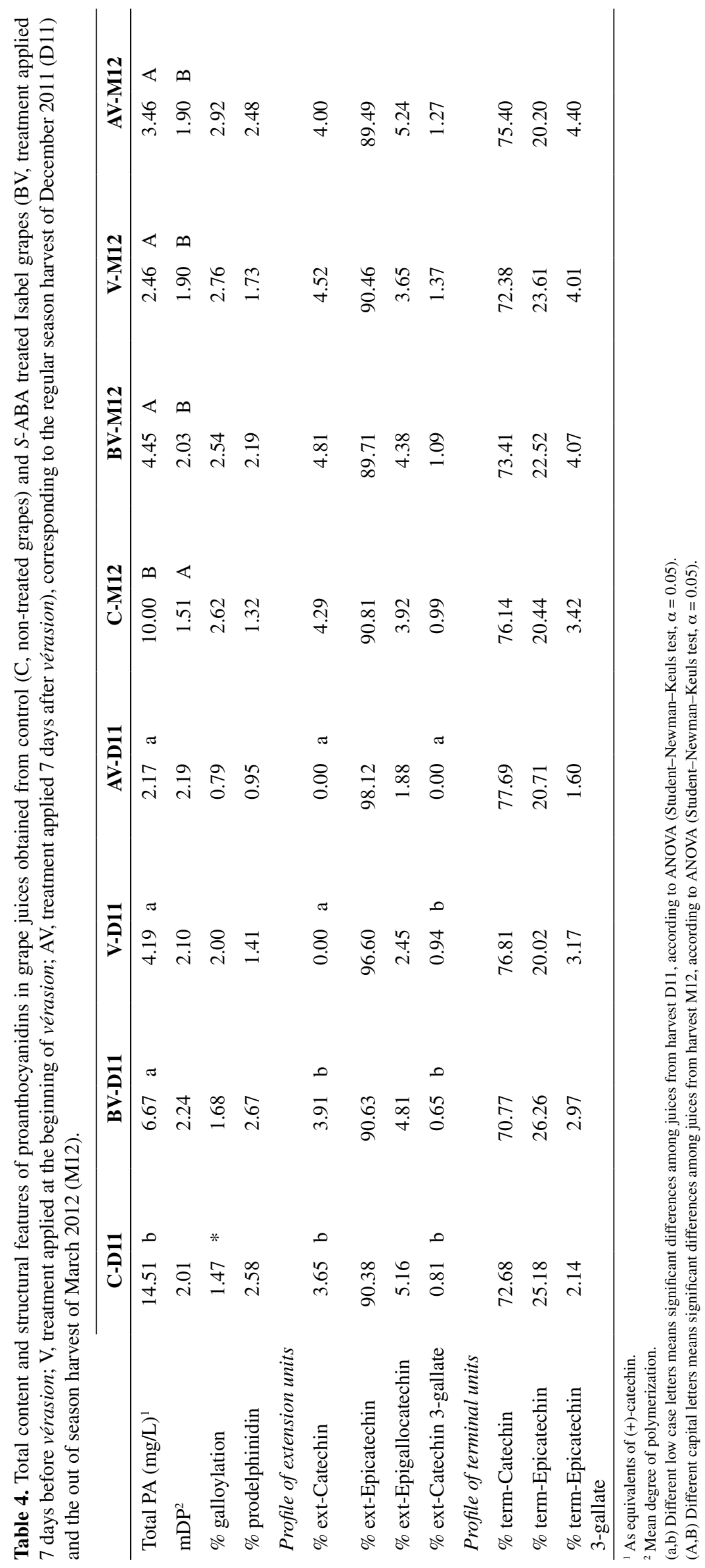




\section{References}

[1] U.A. Camargo, J.D.G. Maia, P.S. Ritschel. Novas cultivares brasileiras de uva. (Embrapa Uva e Vinho: Bento Gonçalves, 2010).

[2] A. Azuma, S. Kobayashi, N. Goto-Yamamoto, M. Shiraishi, N. Mitani, H. Yakushiji, Y. Koshita. Plant Sci., 176 (2009)

[3] T. Ban, M. Ishimaru, S. Kobayashi, S. Shiozaki, N. Goto-Yamamoto, S. Horiuchi. J. Hortic. Sci. Biotech., 78 (2003).

[4] S. Hiratsuka, H. Onodera,Y. Kawai, T. Kubo, H. Itoh, R. Wada. Sci. Hortic. 90 (2001).

[5] S.J. Owen, M.D. Lafond, P. Bowen, C. Bogdanoff, K. Usher, S. R. Abrams Am. J. Enol. Viticult. 60 (2006).

[6] M.C. Cantín, M.W. Fidelibus, C.H. Crisosto. Postharvest Biol. Tec. 46 (2007).

[7] M.C. Peppi, M.W. Fidelibus, N. Dokoozlian. J. Hortic. Sci. Biotech. 82 (2007).

[8] M.C. Peppi, M.W. Fidelibus, N. Dokoozlian. Int. J. Fruit Sci. 7 (2007).

[9] R. Koyama, A.M. Assis, L.Y. Yamamoto, F.W. Borges, R.S. Borges. Hortscience. 49 (2014).

[10] M. Giribaldi, W. Hartung, A. Schubert. J. Int. Sci. Vigne Vin. 44 (2011).

[11] R.S. Borges, G.A. Silva, S.R. Roberto, A.M. Assis, L.Y. Yamamoto. Sci. Hortic. 161 (2013).

[12] L.P.G. Rebello, E.S. Lago-Vanzela, M.T. Barcia, A.M. Ramos, P.C. Stringheta, R. Da-Silva, N. Castillo-Muñoz, S. Gómez-Alonso, I. HermosínGutiérrez. Food Res. Int. 54 (2013).

[13] N. Castillo-Muñoz, S. Gómez-Alonso, E. GarcíaRomero, M.V. Gómez, A. Velders, I. HermosínGutiérrez. J. Agr. Food Chem., 57 (2009).

[14] S. L. Nixdorf, I. Hermosín-Gutiérrez, I. Anal. Chim. Acta. 659 (2010).
[15] E.S. Lago-Vanzela, R. Da-Silva, E. Gomes, E. García-Romero, I. Hermosín-Gutiérrez. J. Agr. Food Chem. 59 (2011).

[16] M J. Cejudo-Bastante, I. Hermosín-Gutiérrez, M.S. Pérez-Coello. Food Chem. 124 (2011).

[17] D. Blanco-Vega, S. Gómez-Alonso, I. HermosínGutiérrez. Food Chem. 158 (2014).

[18] J. Ribéreau-Gayon, E. Peynaud, P. Sudraud, P. Ribéreau-Gayon. Traité d'Enologie. (Tome 1. Sciences et Techniques du Vin, Dunod, Paris. 1972).

[19] W. Brand-Williams, M.E. Cuvelier, C. Berset. Lebensm.Wiss. Technol. 28 (1995).

[20] E.S. Lago-Vanzela, D.P. Procópio, E.A.F. Fontes, A.M. Ramos, P.C. Stringheta, R. Da-Silva, N. Castillo-Muñoz, I. Hermosín-Gutiérrez. Food Res. Int. 56 (2014).

[21] V. Cheynier, M. Dueñas-Paton, E. Salas, C. Maury, J.M. Souquet, P. Sarni-Manchado. Am. J. Enol. Viticult. 57 (2006).

[22] D. Blanco-Vega, F.J. López-Bellido, J.M. AlíaRobledo, I. Hermosín-Gutiérrez. J. Agr. Food Chem. 59 (2011).

[23] F. Weber, P. Winterhalter. Food Res. Int. 65 (2014).

[24] E.S. Lago-Vanzela, R. Da-Silva, E. Gómes, E. García-Romero, I. Hermosín-Gutiérrez. J. Agr. Food Chem, 59 (2011).

[25] C. Malien-Aubert, O. Dangles, M.J. Amiot. J. Agr. Food Chem, 49 (2001).

[26] N. Castillo-Muñoz, S. Gómez-Alonso, E. GarcíaRomero, I. Hermosín-Gutiérrez. J. Agr. Food Chem. 55 (2007).

[27] I. Hermosín-Gutiérrez, N. Castillo-Muñoz, S. GómezAlonso, E. García-Romero. ACS Symposium Series, 1081 (2011) 